\title{
Review: Application of Nanoparticles in Urothelial Cancer of the Urinary Bladder
}

\author{
Chieh-Hsiao Chen ${ }^{1,2} \cdot$ Tzu-Min Chan $^{3} \cdot$ Yi-Jhen Wu ${ }^{1} \cdot J^{\text {Ja-Jin Chen }}{ }^{1}$
}

Received: 25 May 2015/ Accepted: 27 July 2015/Published online: 11 August 2015

(c) The Author(s) 2015. This article is published with open access at Springerlink.com

\begin{abstract}
Bladder cancer is a common malignancy of the urinary tract, which generally develops in the epithelial lining of the urinary bladder. The specific course of treatment depends on the stage of bladder cancer; however, therapeutic strategies typically involve intravesical drug delivery to reduce toxicity and increase therapeutic effects. Recently, metallic, polymeric, lipid, and protein nanoparticles have been introduced to aid in the treatment of bladder cancer. Nanoparticles are also commonly used as pharmaceutical carriers to improve interactions between drugs and the urothelium. In this review, we classify the characteristics of bladder cancer and discuss the types of nanoparticles used in various treatment modalities. Finally we summarize the potential applications and benefits of various nanoparticles in intravesical therapy.
\end{abstract}

Keywords Urothelial cancer - Nanoparticles ·

Nanotechnology · Photothermal Therapy · Drug delivery

\section{Introduction}

Urothelial cancer of urinary bladder is an epithelial cancer in which abnormal cells in the epithelial lining multiply without control $[1,2]$. The most common type of bladder

Chieh-Hsiao Chen

jerrychen119@gmail.com

1 Institute of Biomedical Engineering, National Cheng Kung University, 1 University Road, Tainan 701, Taiwan

2 Department of Urology, China Medical University Beigang Hospital, 123 Sin-Der Road, Beigang 651, Yunlin, Taiwan

3 Department of Medical Education and Research, China Medical University Beigang Hospital, 123 Sin-Der Road, Beigang 651, Yunlin, Taiwan cancer is transitional cell carcinoma (TCC), also referred to as urothelial cell carcinoma (UCC). Over the last two decades, various nanoparticle technologies have been used in the detection and treatment of cancers of the breast [3], oral cavity [4], lung [5], cervix [6], and brain [7]. Nanoparticles are also used as pharmaceutical carriers in drug delivery systems comprising organic and inorganic materials [8, 9], and many state-of-the-art techniques incorporate liposomal [10], polymer-drug conjugates [11] and micellar formulations [12]. Furthermore, a considerable number of nanoparticle platforms are currently in the preclinical stages of development [13]. In this review, we classify the various types of bladder cancer according to their clinical characteristics and summarize how various nanoparticles are applied in intravesical bladder cancer therapy. This work is of particular importance at this time, due to recent findings showing that the use of nanoparticles in the treatment of urothelial cancer in the urinary bladder can reduce negative side effects and recurrence rates.

\section{Current Treatment of Urothelial Cancer of the Urinary Bladder}

Bladder carcinomas the fourth most common malignancy in America and the fifth most common disease among European males [14]. Furthermore, the prevalence of this malignancy of the urinary tract tends to increase with economic development [15-17]. The most typical symptom of this malignancy is painless hematuria, with microscopic or gross hematuria presenting in more than $85 \%$ of patients [18]. Depending on the severity of hemorrhaging, the color of urine can range from normal, to dark yellow, to bright red or cola [19]. Other symptoms include increased frequency and urgency of urination, dysuria, and abdominal pain [20]. 
The five-year average survival rate among patients with bladder cancer is approximate $60 \%$; however, bladder cancer is associated with a high recurrence rate, which results in a longer course of disease with greater per-patient financial cost compared to other cancers [21].

The bladder is a hollow, distensible organ used for the storage of urine [22]. It is composed of mucosa, submucosa, detrusor muscle, and perivesical fat. Bladder cancer typically begins in the mucosa layer, namely, transitional epithelial tissue [23]. TCC comprises over $90 \%$ of bladder cancers; other bladder cancer types include squamous cell carcinoma (SCC, about 7-8 \%), adenocarcinoma (1-2\%), and carcinosarcoma $(<1 \%)$ [24]. Furthermore, most diagnosed cases (70-85\%) involve a superficial (non-muscle invasive) form of the disease [25-27]. Bladder cancer staging is classified according to the location and spread of tumors (i.e. stage Tis, Ta and T1-4; Fig. 1), and how to directly against superficial bladder cancer is a key issue that must be resolved in order to improve disease prognosis [28-31].

Determining the appropriate course of treatment depends on the stage of bladder cancer [32,33]. In the case of non-invasive bladder tumors, the gold standard of primary therapy is transurethral resection of the bladder tumor (TUR-BT), which allows the bladder to retain functionality; however, TUR-BT commonly results in tumor relapse [21]. This has led to the widespread use of Bacillus Calmette-Guérin (BCG) [34] or chemotherapy agents [35], such as Mitomycin C, Adriamycin, Epirubicin or Thiotepa, as adjuvant therapies through intravesical instillation. Chemical agents [36-38], such as Mitomycin C, can restrain the DNA, RNA, and proteins to suppress the proliferation of cancer cells. However, these agents have a number of negative side effects, such as chemical cystitis

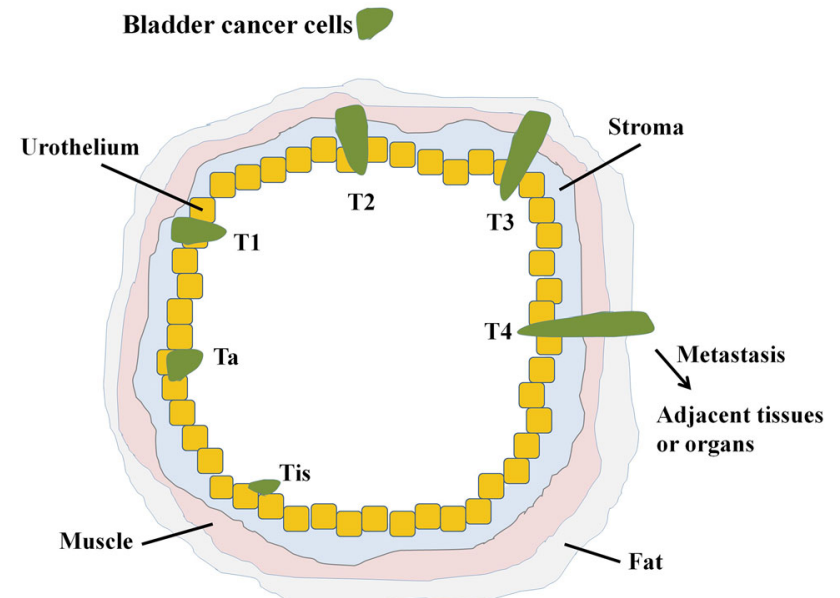

Fig. 1 A schematic diagram illustrating the classification of bladder cancer: Tis carcinoma in situ ('flat tumour'); $T 1$ tumour invades subepithelial connective tissue; $T 2$ tumour invades muscle; $T 3$ tumour invades perivesical tissue; $T 4$ tumour invades prostate, uterus, or vagina and other irritating symptoms. Furthermore, long-term chemical cystitis can lead to bladder contraction and a reduction in functionality. Patients suffering from unfavorable differentiation associated with the recurrences of cancer are generally administered intravesical therapy in the form of immune agent BCG [39, 40]. Adverse reactions to these chemical therapies include cystitis $(67 \%)$, fever (25\%), haematuria (23\%), and/or increased frequency of urination (71\%) [41]. In some cases, the use of these treatments has been associated with severe toxicity, leading to septicemia, disseminated intravascular coagulation, and multiple organ failure, which can reduce a patient's desire to be treated [42-44].

Despite the fact that BCG is currently the most commonly used intravesical therapy in superficial bladder cancer treatment, many studies have reported that this agent is only able to delay early recurrence [45]. Furthermore, the widespread use of BCG and chemotherapy causes bladder cancer patients to suffer from high rates of recurrence and rapid disease progression [46, 47]. Thus, compared with other instillation agents, BCG appears somewhat limited in its therapeutic effectiveness [48]. Conversely, nanoparticle technology, which has been used in recent years, has shown great promise in increasing the efficacy of drugs and preventing adverse reactions. The field of medicine stands to benefit significantly from advances in nanotechnology, specifically from improvements in detection imaging and tumor therapy [49]. Nanoparticle technologies were developed to be controlled drug delivery systems with unique targeting for cancer treatment [50]. Many kinds of delivery systems have been developed for bladder cancer therapy using different materials and types of nanoparticles, such as metal/gold, polymeric, liposome and lipid, and protein nanoparticles.

\section{Application of Nanoparticles in Urinary Bladder Cancer}

\subsection{Metal/Gold Nanoparticles}

Metal nanoparticles are widely used in engineering as well as biomedical sciences [51]. These include magnetic nanoparticles "Fe3O4, Fe-Au alloy" [52, 53] as well as gold [54] and silver [55] nanoparticles, which may be conjugated with antibodies, ligands, or other drugs in order to modify functional groups [56]. Important developments are being made in the field of nanotechnology for applications in magnetic separation, the enrichment of the target analytes, targeted drug delivery, targeted gene delivery, and diagnostic imaging. Important imaging modalities which aid in the visualization of disease states, include MRI, CT, PET, ultrasound, SERS, and optical imaging [57-61]. 
Because of outstanding biocompatibility, gold was among the first metallic biomaterial to be developed [62]. Furthermore, gold nanoparticles (GNPs) have strong spectral absorption properties when the diameter of the gold particle is smaller than the wavelength of the incoming ray [63]. When nanoparticles absorb energy at a specific wavelength, conduction band electrons from the surface of the particle become polarized and produce instantaneous dipole forces, leading to coherent dipole oscillation in a phenomenon referred to as surface plasma resonance (SPR) [64-66]. Various factors affect the properties of SPR, such as size, shape of the nanoparticles as well as other variables related to chemical structure. The absorption wavelength presents a non-linear red shift associated with the diameter or aspect ratio of the gold nanoparticles.

Laser induced thermotherapy involves the use of a laser to induce heat in tissue, which in-turn leads to coagulative necrosis that destroys tumor cells [67-69]. Plasmonic photothermal therapy (PPTT) applies the optical properties of SPR to assist laser-induced thermotherapy. This technique uses GNPs to enhance the effects of target therapy $[69,70]$. Specifically, GNPs absorb specific wavelengths of light suitable for the generation of thermal energy while enhancing spatial selectivity in the application of hyperthermia therapy. One novel adjuvant therapy based on heat effects involves the use of specially designed nanomaterials with high photothermal conversion capability, such as nanospheres, nanoshells, nanorods, nanocages [69]. This treatment provides obvious benefits even after a short treatment time and achieves a hyperthermic state with relatively low laser power, thereby avoiding injury to adjacent healthy tissue.

GNPs provide excellent biocompatibility, modulability, and optical properties [71, 72]. In addition, GNPs are able to modify particular nucleic acids and protein molecules to facilitate the rapid detection of abnormal genes or cancer cells, which makes it possible to diagnose diseases more quickly and easily [73]. The superior photothermal properties of GNPs, compared with other nanoparticles (e.g. core-shell silica nanoparticles, magnetic nanoparticles, cerium oxide " $\mathrm{CeO} 2, \mathrm{TiO} 2, \mathrm{ZnO}$ ", and quantum dots), has resulted in a gradual shift from these materials to the use of GNPs [69]. GNPs also provide excellent chemical stability and a strong affinity to biomolecules, which facilitates the detection and treatment of cancer. Indeed, the biocompatibility and non-cytotoxic properties of GNPs have the greatest potential for future clinical applications. Thus far, GNPs have been most widely applied in the treatment of breast cancer, oral cavity cancer, lung cancer, cervical and brain cancer [74-76]. Indeed, results from previous studies have revealed that GNPs offer obvious therapeutic benefits to cancer patients. For example, in one study, exposure to a laser was shown to damage cancer cells; however, GNPs require only half the laser power of regular laser treatment [69]. Combining particles with antibodies or proteins that target the overexpressed antigen in the tumor has also been shown to enhance the therapeutic benefits [69].

Previous studies have reported the application of modified gold nanoparticles in bladder cancer. These modified nanoparticles include gum arabic-coated radioactive [77], hyaluronic acid functionalized fluorescent [54], epigallocatechin-3-gallate [75], and antibody-coated silica nanoshells $[78,79]$. To destroy tumor cells and preserve normal cells, a targeting system is required. In target therapy, monoclonal antibodies serve as the aiming system of nanoparticles. For different cancer cells, individualized targets are chosen according to the expression of antigens, such as transferring, Her-2, and epidermal growth factor receptor (EGFR) in breast cancer [80-82] and EGFR in oral and epidermal cancers [83, 84]. Globally, bladder cancer is a common cause of carcinomatosis. To target bladder cancer, EGFR, mucin 7, and cytokeratin 20 are commonly used [85-87]. Figure 2, the TEM, shows the bladder cancer cell is targeted by antibody modified GNPs and some endocytosis is found.

\subsection{Polymeric Nanoparticles}

Polymeric nanoparticles can be made from a wide range of polymers, including natural or synthetic substances composed of macromolecules such as "poly(lactide-coglycolide)", "poly(lactic acid)", "poly(e-caprolactone)", "chitosan", and "poly(alkyl cyanoacrylates)" [88-91]. However, many polymeric nanoparticles are toxic to patients; therefore, improving biocompatibility and reducing cytotoxicity of polymeric nanoparticles is imperative for biomedical applications. The composition of polymeric nanoparticles can be varied for the

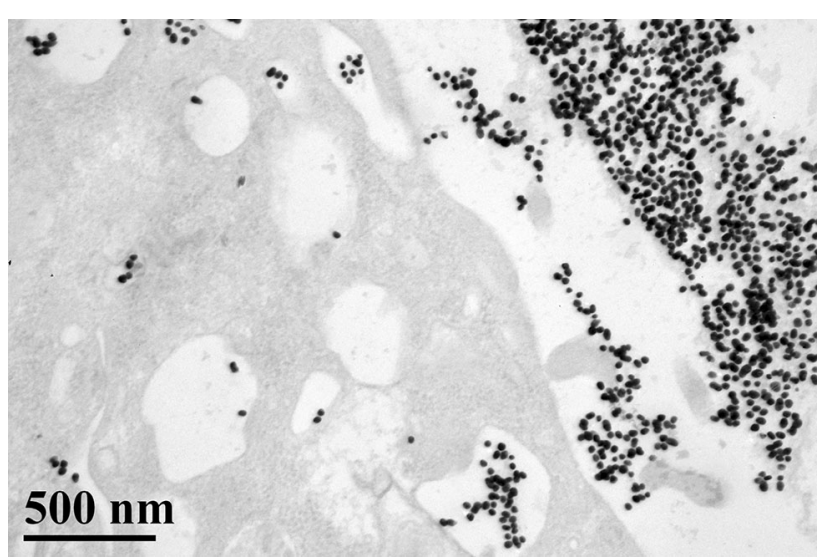

Fig. 2 TEM $(\times 60,000)$ illustrates that the bladder cancer cell is targeted by antibody (anti-EGFR) modified GNPs. Endocytosis is noticed 
delivery of specific drugs to the surface of specific cells [91]. The first step in using a polymeric carrier is the design a polymeric structure that is biodegradable to ensure that they retain their properties in vivo only for as long as needed. Specifically, biodegradability ensures that polymeric carriers degrade into small molecules that can be metabolized and excreted from the body. Previous studies on the treatment of bladder cancer with drugs formulated by polymeric nanoparticles have shown considerable promise [92, 93]. Compared with other drug delivery systems, polymeric nano-carriers are easier to synthesize, less expensive, and provide superior biocompatibility and biodegradability. They are also non-immunogenic, non-toxic, and water soluble.

\subsection{Liposome and Lipid Nanoparticles}

Liposomes are artificially-synthesized mono-layer or bilayer phospholipid vesicles, which have been developed for the transport of molecules, such as drug molecules, nucleotides, protein, and plasmids [94, 95]. Previous studies have indicated that large negatively-charged multilamellar vesicles improve binding affinity and increase the inhibition of four various human bladder tumor cell lines: 253J, J82, T24, and TCCSUP [96, 97].

Oncogene overexpression is one of the major causes of urothelial carcinoma; therefore, the silencing of oncogenes via small interfering RNA (siRNA) coated with liposomes may provide an effective approach to the prevention of bladder cancer [98, 99]. Moreover, the intravesical instillation of liposomes encapsulated with cytotoxic agents has been found to improve the efficacy of intravesical therapies used in the treatment of bladder cancer [100, 101]. Indeed, one highly feasible treatment modality involves intravesical administration of plasmid-containing liposomes, such as IL2 [102, 103], IL-4 [104], IL-12 [105], interferon-gamma [106], and granulocyte macrophage colony-stimulating factor [107]. Furthermore, in a number of clinical trials, it has been found that intravesical liposomes have similar therapeutic efficacy and can improve the pain score of patients without unanticipated adverse effects [108, 109].

Two lipid nanoparticle systems have previously been applied in cancer therapy: solid lipid nanoparticles (SLNs) and nanostructured lipid carriers (NLCs), both of which are composed of lipids instead of phospholipids [110-112]. SLNs are prepared from a single purified lipid and forma crystalline lattice which allows the incorporation of small molecular drugs. NLCs allow a mixture of lipid types to create a lipid matrix as imperfect as possible. Because of their unique size dependent properties, SLNs are at the forefront of the rapidly developing field of nanotechnology, with numerous potential applications in drug delivery [113]. The ability to incorporate drugs into nanocarriers offers a new vehicle for drug delivery that could be used to improve drug targeting. Indeed, over the past few years, nanostructured lipid carriers have been attracting considerable interest as alternative carriers for anticancer pharmaceuticals. However, many anticancer mixtures are limited with regard to solubility and specificity and are toxic to normal tissue [114]. These mixtures are also associated with poor specificity and steadiness, pharmaceutical resistance, rapid degradation, the need for largescale output procedures, a fast release of the pharmaceutical from its carrier scheme, the residues of the organic solvents utilized in the output method and the toxicity from the polymer with esteem to the carrier scheme are anticipated to be overcome through use of the nanostructured lipid carrier.

\subsection{Protein Nanoparticles}

Colloidal drug carrier systems provide selective drug targeting through the use of modified protein nanoparticles, which reduces the effects of drug toxicity $[78,115]$. Protein materials used in vivo solves the enzyme-induced degradable problem and provides considerable advantages over colloidal carriers, such as liposomes and cell ghosts. They are composed of biological components capable of delivering a range of molecules, both large and small. Indeed, protein nanoparticles have already been employed as pharmaceutical carriers in a number of cancer therapies $[97,116]$. For example, protein nanoparticles can be used in the delivery of protein therapeutics to the lung. They can also be incorporated into biodegradable polymer microspheres/nanospheres to facilitate the controlled release depot or oral delivery. Many researchers are currently focused on the preparation of nanoparticles using proteins such as albumin, gelatin, gliadin, and legumin. In intravesical therapy, commercial paclitaxel contains Cremophor, which can cause micelle formation and interfere with the transportation of paclitaxel across the urothelium. To improve the delivery of paclitaxel in intravesical therapy against bladder cancer, Lu et al. [117] developed a paclitaxel-loaded gelatin protein nanoparticle. Results from that study as well as other research have demonstrated the potential of protein nanoparticles as drug delivery systems for parenteral, peroral, and ocular administration, and may also be a vaccine adjuvant.

\section{Discussion and Conclusions}

The aim of using nanoparticles in cancer treatment is to increase drug specificity and thereby improve treatment outcomes. Indeed, the unique properties of metallic, polymeric, lipid, and protein nanoparticles have been shown to provide considerable benefits in the treatment of superficial 
urothelial cancer. Intravesical drug delivery is superior to oral therapy in the treatment of bladder cancer, which enables the administration of drugs directly to bladder lesions and reduces the risk of systemic side effects [118]. However, intravesical therapy has limited therapeutic efficacy due to the bladder permeability barrier and periodic bladder discharge. Fortunately, the development of nanoparticles as pharmaceutical carriers has helped to overcome many of these disadvantages. Previous evidence (mostly from animal studies) has supported the application of nanotechnology in intravesical therapy through the retention of drugs in the bladder and the enhancement of drug permeability in bladder cancer [117, 119]. Doubtlessly, nanoparticles will continue to play a dominant role in the coming generations of intravesical therapy against bladder diseases. However, to reduce the risk of distant metastasis, the standard treatment for muscle-invasive bladder cancer remains radical cystectomy, as opposed to regional or systemic drug therapy. As a result, the focus in the application of nanotechnology in bladder cancer treatment remains on non-muscle invasive forms of the disease. Adjuvant therapy in conjunction with nanoparticles lowers the rate of recurrence and reduces the risk of negative side effects associated with traditional intravesical chemotherapy and immune therapy [69].

The excellent photothermal properties of GNPs have led to their application in a variety of treatment techniques which target cancer cells [69, 120, 121]. For example, GNPs can be used to rapidly detect abnormal genes or cancer cells, which improves cancer diagnosis and treatment. In addition, GNPs possess good biocompatibility, good modulability, non-cytotoxicity, and highly specific optical properties. These characteristics suggest that GNPs can benefit a far wider range of clinical applications. Furthermore, differences in electrical charges between GNPs and proteins allow antibody fragments to be conjugated with GNPs [69, 83, 122]. Thus, developing an improved nanoparticle system capable of delivering intact drugs or molecules to the urothelium without severe side effects is a worthy goal for future research.

Open Access This article is distributed under the terms of the Creative Commons Attribution 4.0 International License (http://creative commons.org/licenses/by/4.0/), which permits unrestricted use, distribution, and reproduction in any medium, provided you give appropriate credit to the original author(s) and the source, provide a link to the Creative Commons license, and indicate if changes were made.

\section{References}

1. Wu, B., Cao, X., Liang, X., Zhang, X., Zhang, W., Sunand, G., \& Wang, D. (2015). Epigenetic regulation of Elf5 is associated with epithelial-mesenchymal transition in urothelial cancer. PLoS One, 10, e0117510.
2. Katoh, T., Kaneko, S., Takasawa, S., Nagata, N., Inatomi, H., Ikemura, K., et al. (1999). Human glutathione S-transferase P1 polymorphism and susceptibility to smoking related epithelial cancer; oral, lung, gastric, colorectal and urothelial cancer. Pharmacogenetics and Genomics, 9, 165-169.

3. Zeng, X., Morgensternand, R., \& Nystrom, A. M. (2014). Nanoparticle-directed sub-cellular localization of doxorubicin and the sensitization breast cancer cells by circumventing GSTmediated drug resistance. Biomaterials, 35, 1227-1239.

4. Damascelli, B., Patelli, G., Ticha, V., Di Tolla, G., Frigerio, L. F., Garbagnati, F., et al. (2007). Feasibility and efficacy of percutaneous transcatheter intraarterial chemotherapy with paclitaxel in albumin nanoparticles for advanced squamous-cell carcinoma of the oral cavity, oropharynx, and hypopharynx. Journal of Vascular and Interventional Radiology, 18, 1395-1403.

5. Wehrungand, D., \& Oyewumi, M. O. (2012). Antitumor effect of novel gallium compounds and efficacy of nanoparticle-mediated gallium delivery in lung cancer. Journal of Biomedical Nanotechnology, 8, 161-171.

6. Das, S., Jagan, L., Isiah, R., Rajesh, B., Backianathanand, S., \& Subhashini, J. (2011). Nanotechnology in oncology: Characterization and in vitro release kinetics of cisplatin-loaded albumin nanoparticles: Implications in anticancer drug delivery. Indian Journal of Pharmacology, 43, 409-413.

7. Yin, P. T., Shahand, B. P., \& Lee, K. B. (2014). Combined magnetic nanoparticle-based microRNA and hyperthermia therapy to enhance apoptosis in brain cancer cells. Small (Weinheim an der Bergstrasse, Germany), 10, 4106-4112.

8. Wuand, D., \& Navrotsky, A. (2015). Probing the energetics of organic-nanoparticle interactions of ethanol on calcite. Proceedings of the National Academy of Sciences, 112(17), 53145318.

9. Gu, Y., Dorinand, R. M., \& Wiesner, U. (2013). Asymmetric organic-inorganic hybrid membrane formation via block copolymer-nanoparticle co-assembly. Nano Letters, 13, 53235328.

10. Tamaru, M., Akita, H., Kajimoto, K., Sato, Y., Hatakeyamaand, H., \& Harashima, H. (2014). An apolipoprotein E modified liposomal nanoparticle: ligand dependent efficiency as a siRNA delivery carrier for mouse-derived brain endothelial cells. International Journal of Pharmaceutics, 465, 77-82.

11. Appel, E. A., Tibbitt, M. W., Webber, M. J., Mattix, B. A., Veisehand, O., \& Langer, R. (2015). Self-assembled hydrogels utilizing polymer-nanoparticle interactions. Nature Communications, 6, 6295.

12. Xiao, H., Stefanick, J. F., Jia, X., Jing, X., Kiziltepe, T., Zhangand, Y., \& Bilgicer, B. (2013). Micellar nanoparticle formation via electrostatic interactions for delivering multinuclear platinum(II) drugs. Chemical Communications (Camb), 49, 4809-4811.

13. Alexis, F., Pridgen, E. M., Langerand, R., \& Farokhzad, O. C. (2010). Nanoparticle technologies for cancer therapy. Handbook of Experimental Pharmacology, 197, 55-86.

14. Aziz, A., Shariat, S. F., Roghmann, F., Brookman-May, S., Stief, C. G., Rink, M., et al. (2014). Prediction of cancer-specific survival after radical cystectomy in pT4a urothelial carcinoma of the bladder-development of a tool for clinical decisionmaking. BJU International,. doi:10.1111/bju.12984.

15. Sengupta, N., Siddiquiand, E., \& Mumtaz, F. H. (2004). Cancers of the bladder. The Journal of the Royal Society for the Promotion of Health, 124, 228-229.

16. Siegel, R., Naishadhamand, D., \& Jemal, A. (2012). Cancer statistics, 2012. CA: A Cancer Journal for Clinicians, 62, 10-29.

17. Hongand, Y. M., \& Loughlin, K. R. (2008). Economic impact of tumor markers in bladder cancer surveillance. Urology, 71, 131-135. 
18. Wakuiand, M., \& Shiigai, T. (2000). Urinary tract cancer screening through analysis of urinary red blood cell volume distribution. International Journal of Urology, 7, 248-253.

19. Salawuand, O. T., \& Odaibo, A. B. (2014). Urogenital schistosomiasis and urological assessment of hematuria in preschoolaged children in rural communities of Nigeria. Journal of Pediatric Urology, 10, 88-93.

20. Gardner, J. M., Khurana, H., Leach, F. S., Ayala, A. G., Zhaiand, J., \& Ro, J. Y. (2010). Adenocarcinoma in ectopic prostatic tissue at dome of bladder: a case report of a patient with urothelial carcinoma of the bladder and adenocarcinoma of the prostate. Archives of Pathology \& Laboratory Medicine, 134, 1271-1275.

21. Kondylis, F. I., Demirci, S., Ladaga, L., Kolmand, P., \& Schellhammer, P. F. (2000). Outcomes after intravesical bacillus Calmette-Guerin are not affected by substaging of high grade T1 transitional cell carcinoma. The Journal of Urology, 163, $1120-1123$.

22. Korossis, S., Bolland, F., Ingham, E., Fisher, J., Kearney, J., \& Southgate, J. (2006). Review: tissue engineering of the urinary bladder: considering structure-function relationships and the role of mechanotransduction. Tissue Engineering, 12, 635-644.

23. Amling, C. L. (2001). Diagnosis and management of superficial bladder cancer. Current Problems in Cancer, 25, 219-278.

24. Leung, H. Y., Griffithsand, T. R., \& Neal, D. E. (1996). Bladder cancer. Postgraduate Medical Journal, 72, 719-724.

25. Puntoni, M., Zanardi, S., Branchi, D., Bruno, S., Curotto, A., Varaldo, M., et al. (2007). Prognostic effect of DNA aneuploidy from bladder washings in superficial bladder cancer. Cancer Epidemiology Biomarkers \& Prevention, 16, 979-983.

26. Kirkali, Z., Chan, T., Manoharan, M., Algaba, F., Busch, C., Cheng, L., et al. (2005). Bladder cancer: epidemiology, staging and grading, and diagnosis. Urology, 66, 4-34.

27. Quintero, A., Alvarez-Kindelan, J., Luque, R. J., GonzalezCampora, R., Requena, M. J., Montironiand, R., \& Lopez-Beltran, A. (2006). Ki-67 MIB1 labelling index and the prognosis of primary TaT1 urothelial cell carcinoma of the bladder. Journal of Clinical Pathology, 59, 83-88.

28. Tavora, F., \& Epstein, J. I. (2008). Bladder cancer, pathological classification and staging. BJU International, 102, 1216-1220.

29. Lamm, D. (2007). Bladder cancer: improving care with better classification and risk stratification. Journal of Urology, 178, 1146-1147.

30. Nishiyama, N., Kitamura, H., Maeda, T., Takahashi, S., Masumori, N., Hasegawa, T., \& Tsukamoto, T. (2013). Clinicopathological analysis of patients with non-muscle-invasive bladder cancer: prognostic value and clinical reliability of the 2004 WHO classification system. Japanese Journal of Clinical Oncology, 43, 1124-1131.

31. Sacristan, R., Gonzalez, C., Fernandez-Gomez, J. M., Fresno, F., Escafand, S., \& Sanchez-Carbayo, M. (2014). Molecular classification of non-muscle-invasive bladder cancer (pTa lowgrade, pT1 low-grade, and pT1 high-grade subgroups) using methylation of tumor-suppressor genes. The Journal of Molecular Diagnostics, 16, 564-572.

32. Kamat, A. M., Witjes, J. A., Brausi, M., Soloway, M., Lamm, D., Persad, R., et al. (2014). Defining and treating the spectrum of intermediate risk nonmuscle invasive bladder cancer. The Journal of Urology, 192, 305-315.

33. Anastasiadisand, A., \& De Reijke, T. M. (2012). Best practice in the treatment of nonmuscle invasive bladder cancer. Therapeutic Advances in Urology, 4, 13-32.

34. Patel, S. G., Cohen, A., Weinerand, A. B., \& Steinberg, G. D. (2015). Intravesical therapy for bladder cancer. Expert Opinion on Pharmacotherapy, 16, 889-901.
35. Sirohi, B., Singh, A., Jagannathand, P., \& Shrikhande, S. V. (2014). Chemotherapy and targeted therapy for gall bladder cancer. Indian Journal of Surgical Oncology, 5, 134-141.

36. Xin, Y., Lyness, G., Chen, D., Song, S., Wientjes, M. G., \& Au, J. L. (2005). Low dose suramin as a chemosensitizer of bladder cancer to mitomycin C. The Journal of Urology, 174, 322-327.

37. Staalesen, V., Leirvaag, B., Lillehaugand, J. R., \& Lonning, P. E. (2004). Genetic and epigenetic changes in p21 and p21B do not correlate with resistance to doxorubicin or mitomycin and 5 -fluorouracil in locally advanced breast cancer. Clinical Cancer Research, 10, 3438-3443.

38. He, L. F., Guan, K. P., Yan, Z., Ye, H. Y., Xu, K. X., Renand, L., \& Hou, S. K. (2005). Enhanced sensitivity to mitomycin C by abating heat shock protein 70 expression in human bladder cancer cell line of BIU-87. Chinese Medical Journal-BeijingEnglish Edition, 118, 1965-1972.

39. Ehdaie, B., Sylvesterand, R., \& Herr, H. W. (2013). Maintenance bacillus Calmette-Guerin treatment of non-muscle-invasive bladder cancer: a critical evaluation of the evidence. European Urology, 64, 579-585.

40. Sylvester, R. J. (2011). Bacillus Calmette-Guerin treatment of non-muscle invasive bladder cancer. International Journal of Urology, 18, 113-120.

41. Shelley, M. D., Kynaston, H., Court, J., Wilt, T. J., Coles, B., Burgonand, K., \& Mason, M. D. (2001). A systematic review of intravesical bacillus Calmette-Guerin plus transurethral resection vs transurethral resection alone in Ta and $\mathrm{T} 1$ bladder cancer. BJU International, 88, 209-216.

42. Bohle, A., Jochamand, D., \& Bock, P. R. (2003). Intravesical bacillus Calmette-Guerin versus mitomycin $\mathrm{C}$ for superficial bladder cancer: a formal meta-analysis of comparative studies on recurrence and toxicity. Journal of Urology, 169, 90-95.

43. Schreinemachers, L. M., Van Der Meijden, A. P., Wagenaar, J., Steerenberg, P. A., Feitz, W. F., Groothuis, D. G., et al. (1988). Intravesical and intradermal Bacillus Calmette-Guerin application. A phase I study to the toxicity of a Dutch Bacillus Calmette-Guerin preparation in patients with superficial bladder cancer. European Urology, 14, 15-21.

44. Filardi, M. J., Codish, S. D., Civerchia, L., Howardand, R. K., \& Mckneally, M. F. (1979). Toxicity of intrapleural Bacillus Calmette-Guerin treatment in animals. Cancer Research, 39, 3673-3676.

45. Gardmark, T., Jahnson, S., Wahlquist, R., Wijkstromand, H., \& Malmstrom, P. U. (2007). Analysis of progression and survival after 10 years of a randomized prospective study comparing mitomycin-C and bacillus Calmette-Guerin in patients with high-risk bladder cancer. BJU International, 99, 817-820.

46. Lodde, M., Mian, C., Mayr, R., Comploj, E., Trenti, E., Melotti, R., et al. (2014). Recurrence and progression in patients with non-muscle invasive bladder cancer: prognostic models including multicolor fluorescence in situ hybridization molecular grading. International Journal of Urology, 21, 968-972.

47. Takashi, M., Wakai, K., Hattori, T., Onoand, Y., \& Ohshima, S. (2002). Evaluation of multiple recurrence events in superficial bladder cancer patients treated with intravesical bacillus Calmette-Guerin therapy using the Andersen-Gill's model. International Urology and Nephrology, 34, 329-334.

48. Sylvester, R. J., Brausi, M. A., Kirkels, W. J., Hoeltl, W., Calais Da Silva, F., Powell, P. H., et al. (2010). Long-term efficacy results of EORTC genito-urinary group randomized phase 3 study 30911 comparing intravesical instillations of epirubicin, bacillus Calmette-Guerin, and bacillus Calmette-Guerin plus isoniazid in patients with intermediate- and high-risk stage Ta T1 urothelial carcinoma of the bladder. European Urology, 57, 766-773. 
49. Aliabadi, H. M., Shahin, M., Brocksand, D. R., \& Lavasanifar, A. (2008). Disposition of drugs in block copolymer micelle delivery systems: from discovery to recovery. Clinical Pharmacokinetics, 47, 619-634.

50. Dinauer, N., Balthasar, S., Weber, C., Kreuter, J., Langerand, K., \& Von Briesen, H. (2005). Selective targeting of antibodyconjugated nanoparticles to leukemic cells and primary T-lymphocytes. Biomaterials, 26, 5898-5906.

51. Nossier, A. I., Eissa, S., Ismail, M. F., Hamdyand, M. A., \& Azzazy, H. M. (2014). Direct detection of hyaluronidase in urine using cationic gold nanoparticles: a potential diagnostic test for bladder cancer. Biosensors \& Bioelectronics, 54, 7-14.

52. Zhang, D., Sun, P., Li, P., Xue, A., Zhang, X., Zhangand, H., \& Jin, X. (2013). A magnetic chitosan hydrogel for sustained and prolonged delivery of Bacillus Calmette-Guerin in the treatment of bladder cancer. Biomaterials, 34, 10258-10266.

53. Chung, R.-J., Wangand, H.-Y., Wu, K.-T. (2014). Preparation and characterization of $\mathrm{Fe}-\mathrm{Au}$ alloy nanoparticles for hyperthermia application. Journal of Medical and Biological Engineering.

54. Cheng, D., Han, W., Yang, K., Song, Y., Jiangand, M., \& Song, E. (2014). One-step facile synthesis of hyaluronic acid functionalized fluorescent gold nanoprobes sensitive to hyaluronidase in urine specimen from bladder cancer patients. Talanta, 130, 408-414.

55. Boucher, W., Stern, J. M., Kotsinyan, V., Kempuraj, D., Papaliodis, D., Cohenand, M. S., \& Theoharides, T. C. (2008). Intravesical nanocrystalline silver decreases experimental bladder inflammation. Journal of Urology, 179, 1598-1602.

56. Wang, A. Z., Gu, F., Zhang, L., Chan, J. M., Radovic-Moreno, A., Shaikhand, M. R., \& Farokhzad, O. C. (2008). Biofunctionalized targeted nanoparticles for therapeutic applications. Expert Opinion on Biological Therapy, 8, 1063-1070.

57. Muir, B. W., Acharya, D. P., Kennedy, D. F., Mulet, X., Evans, R. A., Pereira, S. M., et al. (2012). Metal-free and MRI visible theranostic lyotropic liquid crystal nitroxide-based nanoparticles. Biomaterials, 33, 2723-2733.

58. Mizukoshi, Y., Tsuru, Y., Tominaga, A., Seino, S., Masahashi, N., Tanabeand, S., \& Yamamoto, T. A. (2008). Sonochemical immobilization of noble metal nanoparticles on the surface of maghemite: mechanism and morphological control of the products. Ultrasonics Sonochemistry, 15, 875-880.

59. Imran, M., Lee, K. G., Imtiaz, Q., Kim, B. K., Han, M., Choand, B. G., \& Kim, D. H. (2011). Metal-oxide-doped silica nanoparticles for the catalytic glycolysis of polyethylene terephthalate. Journal of Nanoscience and Nanotechnology, 11, 824-828.

60. Liuand, S., \& Han, M. Y. (2010). Silica-coated metal nanoparticles. Chemistry, An Asian Journal, 5, 36-45.

61. Ando, J., Yano, T. A., Fujitaand, K., \& Kawata, S. (2013). Metal nanoparticles for nano-imaging and nano-analysis. Physical Chemistry Chemical Physics: PCCP, 15, 13713-13722.

62. Santos-Martinez, M. J., Rahme, K., Corbalan, J. J., Faulkner, C., Holmes, J. D., Tajber, L., et al. (2014). Pegylation increases platelet biocompatibility of gold nanoparticles. Journal of Biomedical Nanotechnology, 10, 1004-1015.

63. Aiboushev, A., Gostev, F., Shelaev, I., Kostrov, A., Kanaev, A., Museur, L., et al. (2013). Spectral properties of the surface plasmon resonance and electron injection from gold nanoparticles to TiO2 mesoporous film: femtosecond study. Photochemical \& Photobiological Sciences, 12, 631-637.

64. Leeand, K. S., \& El-Sayed, M. A. (2006). Gold and silver nanoparticles in sensing and imaging: sensitivity of plasmon response to size, shape, and metal composition. The Journal of Physical Chemistry B, 110, 19220-19225.

65. Springer, T., \& Homola, J. (2012). Biofunctionalized gold nanoparticles for SPR-biosensor-based detection of CEA in blood plasma. Analytical and Bioanalytical Chemistry, 404, 2869-2875.

66. Gao, H., Shen, W., Lu, C., Liangand, H., \& Yuan, Q. (2013). Surface plasmon resonance additivity of gold nanoparticles for colorimetric identification of cysteine and homocysteine in biological fluids. Talanta, 115, 1-5.

67. Huang, X., Jain, P. K., El-Sayedand, I. H., \& El-Sayed, M. A. (2008). Plasmonic photothermal therapy (PPTT) using gold nanoparticles. Lasers in Medical Science, 23, 217-228.

68. Huang, X., Jain, P. K., El-Sayedand, I. H., \& El-Sayed, M. A. (2007). Gold nanoparticles: interesting optical properties and recent applications in cancer diagnostics and therapy. Nanomedicine (London)., 2, 681-693.

69. Chen, C. H., Wuand, Y. J., \& Chen, J. J. (2015). Gold nanotheranostics: photothermal therapy and imaging of mucin 7 conjugated antibody nanoparticles for urothelial cancer. BioMed Research International, 2015, 813632.

70. Nergiz, S. Z., Gandra, N., Tadepalliand, S., \& Singamaneni, S. (2014). Multifunctional hybrid nanopatches of graphene oxide and gold nanostars for ultraefficient photothermal cancer therapy. ACS Applied Materials \& Interfaces, 6, 16395-16402.

71. Pooja, D., Panyaram, S., Kulhari, H., Rachamallaand, S. S., \& Sistla, R. (2014). Xanthan gum stabilized gold nanoparticles: characterization, biocompatibility, stability and cytotoxicity. Carbohydrate Polymers, 110, 1-9.

72. Osvath, Z., Deak, A., Kertesz, K., Molnar, G., Vertesy, G., Zambo, D., et al. (2015). The structure and properties of graphene on gold nanoparticles. Nanoscale, 7, 5503-5509.

73. Larguinhoand, M., \& Baptista, P. V. (2012). Gold and silver nanoparticles for clinical diagnostics-from genomics to proteomics. Journal of Proteomics, 75, 2811-2823.

74. Eissa, S., Shawky, S. M., Matboli, M., Mohamedand, S., \& Azzazy, H. M. (2014). Direct detection of unamplified hepatoma upregulated protein RNA in urine using gold nanoparticles for bladder cancer diagnosis. Clinical Biochemistry, 47, 104-110.

75. Hsieh, D. S., Wang, H., Tan, S. W., Huang, Y. H., Tsai, C. Y., Yehand, M. K., \& Wu, C. J. (2011). The treatment of bladder cancer in a mouse model by epigallocatechin-3-gallate-gold nanoparticles. Biomaterials, 32, 7633-7640.

76. Peng, G., Tisch, U., Adams, O., Hakim, M., Shehada, N., Broza, Y. Y., et al. (2009). Diagnosing lung cancer in exhaled breath using gold nanoparticles. Nature Nanotechnology, 4, 669-673.

77. Axiak-Bechtel, S. M., Upendran, A., Lattimer, J. C., Kelsey, J., Cutler, C. S., Selting, K. A., et al. (2014). Gum arabic-coated radioactive gold nanoparticles cause no short-term local or systemic toxicity in the clinically relevant canine model of prostate cancer. International Journal of Nanomedicine, 9, 5001-5011.

78. Szlachcic, A., Pala, K., Zakrzewska, M., Jakimowicz, P., Wiedlocha, A., \& Otlewski, J. (2012). FGF1-gold nanoparticle conjugates targeting FGFR efficiently decrease cell viability upon NIR irradiation. International Journal of Nanomedicine, 7 , 5915-5927.

79. Cheng, F. Y., Chenand, C. T., \& Yeh, C. S. (2009). Comparative efficiencies of photothermal destruction of malignant cells using antibody-coated silica@ Au nanoshells, hollow Au/Ag nanospheres and Au nanorods. Nanotechnology, 20, 425104.

80. Press, M. F., Finn, R. S., Cameron, D., Di Leo, A., Geyer, C. E., Villalobos, I. E., et al. (2008). HER-2 gene amplification, HER2 and epidermal growth factor receptor mRNA and protein expression, and lapatinib efficacy in women with metastatic breast cancer. Clinical Cancer Research, 14, 7861-7870.

81. Eghtedari, M., Liopo, A. V., Copland, J. A., Oraevskyand, A. A., \& Motamedi, M. (2009). Engineering of hetero-functional gold nanorods for the in vivo molecular targeting of breast cancer cells. Nano Letters, 9, 287-291. 
82. Li, J. L., Wang, L., Liu, X. Y., Zhang, Z. P., Guo, H. C., Liuand, W. M., \& Tang, S. H. (2009). In vitro cancer cell imaging and therapy using transferrin-conjugated gold nanoparticles. Cancer Letters, 274, 319-326.

83. El-Sayed, I. H., Huangand, X., \& El-Sayed, M. A. (2006). Selective laser photo-thermal therapy of epithelial carcinoma using anti-EGFR antibody conjugated gold nanoparticles. Cancer Letters, 239, 129-135.

84. O'neal, D. P., Hirsch, L. R., Halas, N. J., Payne, J. D., \& West, J. L. (2004). Photo-thermal tumor ablation in mice using near infrared-absorbing nanoparticles. Cancer Letters, 209, 171-176.

85. Bhatia, A., Dey, P., Kumar, Y., Gautam, U., Kakkar, N., Srinivasan, R., \& Nijhawan, R. (2007). Expression of cytokeratin 20 in urine cytology smears: a potential marker for the detection of urothelial carcinoma. Cytopathology : official Journal of the British Society for Clinical Cytology, 18, 84-86.

86. Kinjo, M., Okegawa, T., Horie, S., Nutaharaand, K., \& Higashihara, E. (2004). Detection of circulating MUC7-positive cells by reverse transcription-polymerase chain reaction in bladder cancer patients. International Journal of Urology : Official Journal of the Japanese Urological Association, 11, 38-43.

87. Villares, G. J., Zigler, M., Blehm, K., Bogdan, C., Mcconkey, D., Colinand, D., \& Bar-Eli, M. (2007). Targeting EGFR in bladder cancer. World Journal of Urology, 25, 573-579.

88. Kimand, J., \& Van Der Bruggen, B. (2010). The use of nanoparticles in polymeric and ceramic membrane structures: review of manufacturing procedures and performance improvement for water treatment. Environmental Pollution, 158, 2335-2349.

89. Connolly, D., Currivanand, S., \& Paull, B. (2012). Polymeric monolithic materials modified with nanoparticles for separation and detection of biomolecules: a review. Proteomics, 12, 2904-2917.

90. Beck, R. C., Ourique, A. F., Guterres, S. S., \& Pohlmann, A. R. (2012). Spray-dried polymeric nanoparticles for pharmaceutics: a review of patents. Recent Patents on Drug Delivery \& Formulation, 6, 195-208.

91. Bian, S., Lu, W., Xu, C., Fanand, Y., \& Zhang, X. (2014). In vitro cartilage tissue engineering using porous collagen/PLLA nanoparticle hybrid scaffold. Journal of Medical and Biological Engineering, 34, 36-43.

92. Huang, C., Neoh, K. G., Xu, L., Kangand, E. T., \& Chiong, E. (2012). Polymeric nanoparticles with encapsulated superparamagnetic iron oxide and conjugated cisplatin for potential bladder cancer therapy. Biomacromolecules, 13, 2513-2520.

93. Yan, X., Al-Hayek, S., Huang, H., Zhu, Z., Zhuand, W., \& Guo, H. (2013). Photodynamic effect of 5-aminolevulinic acid-loaded nanoparticles on bladder cancer cells: a preliminary investigation. Scandinavian Journal of Urology, 47, 145-151.

94. Riaz, M. (1995). Review article : stability and uses of liposomes. Pakistan Journal of Pharmaceutical Sciences, 8, 69-79.

95. Baileyand, A. L., \& Sullivan, S. M. (2000). Efficient encapsulation of DNA plasmids in small neutral liposomes induced by ethanol and calcium. Biochimica et Biophysica Acta, 1468, 239-252.

96. Johnson, J. W., Nayar, R., Killion, J. J., Von Eschenbachand, A. C., \& Fidler, I. J. (1989). Binding of liposomes to human bladder tumor epithelial cell lines: implications for an intravesical drug delivery system for the treatment of bladder cancer. Selective Cancer Therapeutics, 5, 147-155.

97. Guhasarkarand, S., \& Banerjee, R. (2010). Intravesical drug delivery: Challenges, current status, opportunities and novel strategies. Journal of Controlled Release, 148, 147-159.

98. Wu, X. R. (2005). Urothelial tumorigenesis: a tale of divergent pathways. Nature Reviews Cancer, 5, 713-725.
99. Barr, F. A., Silljeand, H. H., \& Nigg, E. A. (2004). Polo-like kinases and the orchestration of cell division. Nature Reviews Molecular Cell Biology, 5, 429-440.

100. Killion, J. J., Fan, D., Bucana, C. D., Frangos, D. N., Priceand, J. E., \& Fidler, I. J. (1989). Augmentation of antiproliferative activity of interferon alfa against human bladder tumor cell lines by encapsulation of interferon alfa within liposomes. Journal of the National Cancer Institute, 81, 1387-1392.

101. Frangos, D. N., Killion, J. J., Fan, D., Fishbeck, R., Von Eschenbachand, A. C., \& Fidler, I. J. (1990). The development of liposomes containing interferon alpha for the intravesical therapy of human superficial bladder cancer. Journal of Urology, 143, 1252-1256.

102. Connor, J., Bannerji, R., Saito, S., Heston, W., Fairand, W., \& Gilboa, E. (1993). Regression of bladder tumors in mice treated with interleukin 2 gene-modified tumor cells. Journal of Experimental Medicine, 177, 1127-1134.

103. Porgador, A., Gansbacher, B., Bannerji, R., Tzehoval, E., Gilboa, E., Feldmanand, M., \& Eisenbach, L. (1993). Anti-metastatic vaccination of tumor-bearing mice with IL-2-geneinserted tumor cells. International Journal of Cancer, 53, 471-477.

104. Golumbek, P. T., Lazenby, A. J., Levitsky, H. I., Jaffee, L. M., Karasuyama, H., Bakerand, M., \& Pardoll, D. M. (1991). Treatment of established renal cancer by tumor cells engineered to secrete interleukin-4. Science, 254, 713-716.

105. Brunda, M. J., Luistro, L., Warrier, R. R., Wright, R. B., Hubbard, B. R., Murphy, M., et al. (1993). Antitumor and antimetastatic activity of interleukin 12 against murine tumors. Journal of Experimental Medicine, 178, 1223-1230.

106. Porgador, A., Bannerji, R., Watanabe, Y., Feldman, M., Gilboaand, E., \& Eisenbach, L. (1993). Antimetastatic vaccination of tumor-bearing mice with two types of IFN-gamma gene-inserted tumor cells. The Journal of Immunology, 150, 1458-1470.

107. Dranoff, G., Jaffee, E., Lazenby, A., Golumbek, P., Levitsky, H., Brose, K., et al. (1993). Vaccination with irradiated tumor cells engineered to secrete murine granulocyte-macrophage colonystimulating factor stimulates potent, specific, and long-lasting anti-tumor immunity. Proceedings of the National Academy of Sciences, 90, 3539-3543.

108. Chuang, Y. C., Leeand, W. C., \& Chiang, P. H. (2009). Intravesical liposome versus oral pentosan polysulfate for interstitial cystitis/painful bladder syndrome. Journal of Urology, 182, 1393-1400.

109. Lee, W. C., Chuangand, Y. C., \& Chiang, P. H. (2011). Safety and dose flexibility clinical evaluation of intravesical liposome in patients with interstitial cystitis or painful bladder syndrome. Kaohsiung Journal of Medical Sciences, 27, 437-440.

110. Dasand, S., \& Chaudhury, A. (2011). Recent advances in lipid nanoparticle formulations with solid matrix for oral drug delivery. AAPS PharmSciTech., 12, 62-76.

111. Das, S., Ngand, W. K., \& Tan, R. B. (2014). Sucrose ester stabilized solid lipid nanoparticles and nanostructured lipid carriers. II. Evaluation of the imidazole antifungal drug-loaded nanoparticle dispersions and their gel formulations. Nanotechnology, 25, 105102.

112. Souto, E. B., Wissing, S. A., Barbosaand, C. M., \& Muller, R. H. (2004). Comparative study between the viscoelastic behaviors of different lipid nanoparticle formulations. Journal of Cosmetic Science, 55, 463-471.

113. Kang, M. R., Yang, G., Place, R. F., Charisse, K., EpsteinBarash, H., Manoharanand, M., \& Li, L. C. (2012). Intravesical delivery of small activating RNA formulated into lipid nanoparticles inhibits orthotopic bladder tumor growth. Cancer Research, 72, 5069-5079. 
114. Nakamura, T., Fukiage, M., Higuchi, M., Nakaya, A., Yano, I., Miyazaki, J., et al. (2014). Nanoparticulation of BCG-CWS for application to bladder cancer therapy. Journal of Controlled Release, 176, 44-53.

115. Lohcharoenkal, W., Wang, L., Chen, Y. C., \& Rojanasakul, Y. (2014). Protein nanoparticles as drug delivery carriers for cancer therapy. BioMed Research International, 2014, 180549.

116. Weber, C., Coester, C., Kreuter, J., \& Langer, K. (2000). Desolvation process and surface characterisation of protein nanoparticles. International Journal of Pharmaceutics, 194, 91-102.

117. Lu, Z., Yeh, T. K., Tsai, M., Auand, J. L., \& Wientjes, M. G. (2004). Paclitaxel-loaded gelatin nanoparticles for intravesical bladder cancer therapy. Clinical Cancer Research, 10, $7677-7684$.

118. Zhou, D., Zhangand, G., \& Gan, Z. (2013). c(RGDfK) decorated micellar drug delivery system for intravesical instilled chemotherapy of superficial bladder cancer. Journal of Controlled Release, 169, 204-210.
119. Chang, L. C., Wu, S. C., Tsai, J. W., Yuand, T. J., \& Tsai, T. R. (2009). Optimization of epirubicin nanoparticles using experimental design for enhanced intravesical drug delivery. International Journal of Pharmaceutics, 376, 195-203.

120. Lu, W., Arumugam, S. R., Senapati, D., Singh, A. K., Arbneshi, T., Khan, S. A., et al. (2010). Multifunctional oval-shaped goldnanoparticle-based selective detection of breast cancer cells using simple colorimetric and highly sensitive two-photon scattering assay. ACS Nano, 4, 1739-1749.

121. Von Maltzahn, G., Park, J. H., Agrawal, A., Bandaru, N. K., Das, S. K., Sailorand, M. J., \& Bhatia, S. N. (2009). Computationally guided photothermal tumor therapy using long-circulating gold nanorod antennas. Cancer Research, 69, 3892-3900.

122. Ackerson, C. J., Sykesand, M. T., \& Kornberg, R. D. (2005). Defined DNA/nanoparticle conjugates. Proceedings of the National Academy of Sciences of the United States of America, 102, 13383-13385. 